\title{
HEART FAILURE IN PATIENTS WITH HIGH BLOOD PRESSURE
}

\author{
BY \\ J. N. MICKERSON \\ From the Cardiac Department, Charing Cross Hospital
}

Received August 21, 1958

In the course of four years work in a clinic for the investigation and follow up of high blood pressure, the impression has been gained that although hypertension may increase greatly the work of the heart, the heart does not fail unless some additional embarrassment is imposed. Hypotensive drugs have, by reducing the work load of the heart, increased the relative importance of these additional factors.

It has for long been accepted that heart failure is a common complication and a major cause of death in patients with high blood pressure. Thus the mortality from this cause found by Bell and Clawson (1928) was 44 per cent; that recorded by Murphy et al. (1932) 50 per cent; by Fahr (1935) 55 per cent; and by Clawson (1941) 43 per cent.

It is the purpose of this paper to assess the cause or causes, over and above overwork of the left ventricle, that bring about failure in this common malady.

\section{MATERIAL}

The case histories of all patients admitted to the medical wards over the ten-year period 19461955 were examined. During this time 348 hypertensive patients were admitted in heart failure. Of these 7 died within a few hours of admission and have been excluded from the series, since they could not be accurately assessed with regard to history, blood pressure, and electrocardiography. The case histories of the remaining 341 patients, comprising 184 men and 157 women, were reviewed critically from the standpoint of the manner in which their heart failure developed.

\section{CRITERIA}

High Blood Pressure. Difficulty is encountered when an attempt is made to define high blood pressure. There is no agreement upon a pressure level above which a patient may be considered to have hypertension. In this respect Hamilton et al. (1954) have drawn attention to the progressive increase of systolic blood pressure found normally with advancing years; it is likely that many patients with so-called essential hypertension may not in fact have pathologically elevated blood pressures, their pressure levels falling within the upper limit of normality on the distribution curve.

Since it is generally agreed that a high diastolic pressure is of greater significance than a high systolic pressure, only patients with a diastolic pressure of 90 or more were accepted. In most the systolic pressure exceeded 180. Those with systolic pressures between 150 and 180 were included when their associated diastolic pressure was 110 .

The diastolic pressure was not assessed while a patient was in acute left ventricular failure, since wide fluctuations, particularly elevation, of the blood pressure level occur during such episodes (Fishberg, 1940). In some instances the blood pressure was known prior to the onset of failure; in most, the accepted pressure level was that noted after failure had subsided and usually just before discharge from hospital. Of the 10 patients who died and in whom congestive heart failure had persisted, the average pressure after admission was considered to reflect their usual blood pressure.

Heart Failure. Patients with evidence of failure of either ventricle were included. For the 
purposes of analysis patients were separated into three groups: (i) those with acute left ventricular failure, i.e. attacks of paroxysmal dyspnœa or of acute pulmonary œdema; (ii) patients in congestive heart failure with jugular venous and hepatic congestion and sometimes dependent œdema, and (iii) patients with both congestive and left ventricular failure.

Ischamic Heart Disease. A diagnosis of ischæmic heart disease was accepted when one of the following criteria was present.

(i) An unquestionable history of angina of effort with or without the cardiographic pattern of ischæmia, either at rest or provoked by a test exercise.

(ii) Cardiographic evidence of myocardial infarction. Most patients in whom this was present gave a history of prolonged chest pain and also had the associated phenomena characteristic of cardiac infarction. That infarction was usually of at least moderate severity was shown by the fact that more than 90 per cent of the cardiograms showing cardiac infarction had pathological $Q$ waves. In the absence of other possible causes, heart block was considered to be due to coronary artery disease.

(iii) The finding of a myocardial infarction at necropsy.

\section{RESULTS}

A cause of heart failure in addition to hypertension was found in all but 10 ( 3 per cent) of the 341 patients with high blood pressure.

The diseases that precipitated heart failure were considered under two main groups of "renal" and "non-renal" causes. Included in the group of renal causes (79 cases) were patients with evidence of renal disease alone or in combination with cardiac lesions and also patients with malignant hypertension, since this condition is associated with renal vascular damage. The remaining patients with a known cause of heart failure formed the group of non-renal causes (252 cases) (Table I).

TABLE I

Causes of Heart failure in Patients with High Blood Pressure

\begin{tabular}{|c|c|c|c|c|c|c|c|c|}
\hline \multicolumn{4}{|c|}{ Cause of heart failure } & \multirow{2}{*}{$\begin{array}{c}\begin{array}{c}\text { Number } \\
\text { of } \\
\text { patients }\end{array} \\
27 \\
23 \\
29 \\
79\end{array}$} & \multirow{2}{*}{$\begin{array}{c}\begin{array}{c}\text { Average } \\
\text { age } \\
\text { (years) }\end{array} \\
- \\
- \\
54 \cdot 1\end{array}$} & \multirow{2}{*}{$\begin{array}{c}\text { Died } \\
10 \\
10 \\
13 \\
33\end{array}$} & \multirow{2}{*}{$\begin{array}{c}\begin{array}{c}\text { Average } \\
\text { age at } \\
\text { death } \\
\text { (years) }\end{array} \\
- \\
- \\
53.8\end{array}$} & \multirow{2}{*}{$\begin{array}{c}\text { Mortality } \\
37 \% \\
44 \% \\
45 \% \\
42 \%\end{array}$} \\
\hline $\begin{array}{l}\text { Combined cardiac and re } \\
\text { Renal lesions ... } \\
\text { Malignant hypertension } \\
\text { Total of renal cases ... }\end{array}$ & $\begin{array}{c}\text { al le } \\
\cdots \\
\cdots \\
\cdots\end{array}$ & $\begin{array}{l}\text { ns } \\
\cdots \\
\cdots \\
\cdots\end{array}$ & $\begin{array}{l}\cdots \\
\cdots \\
\cdots \\
\cdots\end{array}$ & & & & & \\
\hline $\begin{array}{l}\text { Cardiac ischæmia } \\
\text { Valvular lesions } \\
\text { Respiratory infections } \\
\text { Miscellaneous } \\
\text { Total of non-renal cases }\end{array}$ & $\begin{array}{l}\cdots \\
\cdots \\
\cdots \\
\cdots\end{array}$ & $\begin{array}{l}\cdots \\
\cdots \\
\cdots \\
\cdots \\
\cdots\end{array}$ & $\begin{array}{l}\cdots \\
\cdots \\
\cdots \\
\cdots\end{array}$ & $\begin{array}{r}172 \\
37 \\
20 \\
23 \\
252\end{array}$ & $\frac{62}{-}$ & $\begin{array}{r}33 \\
8 \\
6 \\
6 \\
53\end{array}$ & $\frac{65 \cdot 6}{-}$ & $\begin{array}{l}19 \% \\
22 \% \\
30 \% \\
26 \% \\
21 \%\end{array}$ \\
\hline Total ... & . & . & . & 341 & $60 \cdot 1$ & 86 & $61 \cdot 3$ & $25 \%$ \\
\hline
\end{tabular}

Mortality rate for "renal" cases-men 40.4 per cent, women 43.8 per cent.

Mortality rate for "non-renal" cases-men 22.4 per cent, women 19.5 per cent.

In those instances where several conditions were associated, the one most likely to place an added strain upon the heart was accepted as the factor initiating cardiac failure. Many of these associated conditions, however, excluded as immediate causes of failure, could have contributed 
to its development. Thus obesity occurred in 59 patients (17 per cent); 19 patients (5.6 per cent) had diabetes; mild anæmia was present in 11 ( 3 per cent); thyrotoxicosis in 7 ( 2 per cent); myxœdema 5; prostatic obstruction 4; acromegaly 2; Paget's disease 2; cholecystitis 2; and one case each of Buerger's disease, transverse myelitis, gout, and scleroderma.

Previous hypotensive therapy in 123 patients did not significantly influence the relative frequency of the causes of failure or the prognosis when compared with patients who had not received this treatment.

\section{Renal CAUSES}

These patients had primary kidney disease (e.g. chronic nephritis, pyelonephritis, renal calculus, and hydronephrosis) or malignant hypertension. They were made up as follows.

(a) Isolated renal disease present in 23 patients, 44 per cent of whom died at an average age of 51 years; their total average age was 54 years. The blood urea was raised in 18 patients.

(b) Renal lesions combined with either ischamic heart disease (23 cases) or valvular lesions (4 cases). Each of the 18 men had evidence of cardiac ischæmia; of the 9 women, 5 had associated ischæmia and 4 valvular complications. Their total average age was 60.3 years; 37 per cent died at an average age of 60.6 years.

(c) Malignant hypertension-29 patients. This diagnosis was made when hypertension and albuminuria were associated with papillœdema. Of the 16 men, 4 had angina pectoris and cardiographic evidence of infarction; in two, myocardial infarction was confirmed at necropsy. Two women had angina and evidence of cardiac infarction. Their total average age was 49 years; 45 per cent of them died at an average age of 51 years.

\section{Non-Renal Causes of Heart Failure}

(a) Cardiac Ischcemia. Ischæmic heart disease occurred in half the patients in this series and was by far the commonest immediate cause of heart failure (Table I). It probably contributed to the development of failure in a still larger proportion of patients since evidence of coronary artery disease, in minor degree, was present in a number included in other groups (vide infra). When all such patients were considered there was a 64 per cent incidence of cardiac ischæmia: 71 per cent of men (average age 61 years), and 62 per cent of women (average age 63 years) had either angina pectoris or a myocardial infarction.

Cardiac ischæmia occurred in 158 (65 per cent) of the 246 patients with diastolic pressures below 130, and in 62 (64 per cent) of the 95 patients with pressures above this level.

Acute left ventricular failure was as common as congestive failure; more often a combination of both was present.

Predominant cardiac ischæmia as a cause of heart failure was associated with a mortality rate of 19 per cent. The average age at death was $65 \cdot 6$ years while the survivors averaged 61 years.

(b) Valvular Lesions. The aortic valve, with reguigitation predominating was most frequently involved in men, two-thirds of whom also had ischæmic heart disease. Amongst the 19 women, lesions of the mitral valve occurring in 14 patients were most common; they were followed in frequency by aortic regurgitation and stenosis. One-third of the women had cardiac ischæmia in addition.

Ages averaged 65 years for men and 56 years for women; the presence of associated ischæmia gave an average age of 66 years and merely reflected the higher incidence of coronary disease amongst the men. Without associated ischæmia the average age was 56 years.

Auricular fibrillation was present in 51 per cent of patients with valvular lesions against an incidence of 20 per cent in those without valvular damage.

(c) Respiratory Infections. Bronchopneumonia or bronchitis alone was a precipitating cause of heart failure in 6 per cent of the hypertensive patients in this series; their average age was 66 
years (men 59 years, women 72 years). In the majority of these patients the acute infection was superimposed upon chronic bronchitis and emphysema. A further 44 had chronic bronchitis and emphysema but in these it was not considered to be the major cause of heart failure.

Bronchopneumonia occurred in 26 patients following the development of heart failure and in 13 of these it was the cause of death.

Although a higher incidence of right ventricular failure might be expected in the presence of chronic bronchitis and emphysema, no such bias was found. The frequency of right and of left ventricular failure was the same for those with, as for those without chronic pulmonary disease.

(d) Miscellaneous Lesions. Diseases that precipitated heart failure in this sub-group comprised: thyrotoxicosis, 8 cases; anæmia, 5; paroxysmal tachycardia, 3; paroxysmal auricular fibrillation, 3; and myxœdema, 2. While pulmonary embolus occurred after admission and caused aggravation or recurrence of heart failure that resulted in death in seven instances, it did not occur in any patient as an initial cause of heart failure. No significant conclusions were drawn from this sub-group of patients.

Of the 10 patients in whom no cause other than hypertension was found to account for heart failure, one, a woman aged 43, had a suspected but unproven renal lesion. The remaining patients (average age 59 years) had large hearts. In respect of age they corresponded with the non-renal group. All ten patients had diastolic pressures between 90 and 130. None had received previous hypotensive therapy.

Cause of Death. A combination of several factors contributed to the outcome in the majority of those who died. As the primary cause of death, myocardial infarction occurred in 29 patients; 20 others, all of whom had either a pre-existing renal lesion or malignant hypertension, died in uræmia; respiratory infection caused death in 13; persistent heart failure in 10; pulmonary embolus in 7; cerebral hæmorrhage in 5; in the remaining 2 death was due to mesenteric embolus and carcinoma of the stomach respectively.

\section{Prognosis}

Heart failure developed at a slightly earlier average age in men (59 years) than in women (61 years). The mortality in men (27 per cent) was higher and they died at an earlier age (59 years) than the women ( 24 per cent and 64 years respectively). For all patients heart failure occurred at the age of 60 years and 25 per cent died at an average age of 61 years.

Mortality was unaffected by the presence of auricular fibrillation, the size of the heart, or the type of heart failure that occurred, a similar proportion of patients dying with acute left ventricular failure as with congestive heart failure or a combination of both.

Age exerted some influence upon the mortality rate but was far less important than the presence of a renal lesion. A third factor that appeared to influence the outcome was the height of the blood pressure.

(a) The presence of a renal lesion. A "renal" cause of heart failure carried a mortality rate of 42 per cent, the average age at death being 54 years. In contrast death occurred at an average age of 66 years in only 21 per cent of patients with a "non-renal" cause of failure (Table 1).

(b) Age. After the age of 70 the proportion of ideaths rose considerably as patients reached their allotted span. Below this age the combined mortality rates were higher in the decades up to 60 years than in the seventh decade, being in fact highest in the youngest group of patients (Table II). This discrepancy was explained by the large proportion of patients with a renal lesion (associated with a high mortality) in the younger age groups. Below the age of 50, 44 per cent of the 27 patients in the renal group died, whereas the non-renal group of 29 patients had a corresponding mortality of 14 per cent (Table II).

Among the non-renal group of patients the mortality rate showed a slight but progressive increase with advancing years until the eighth decade when it increased more than threefold. 
TABLE II

Mortality in Relation to Age in Hypertensive Patients with Heart Failure

\begin{tabular}{|c|c|c|c|c|c|c|}
\hline \multirow{2}{*}{\multicolumn{3}{|c|}{ Cause of failure }} & \multicolumn{4}{|c|}{ Age group (years) } \\
\hline & & & $<50$ & $51-60$ & $61-70$ & $>71$ \\
\hline $\begin{array}{l}\text { "Renal" } \\
\text { Number of patients } \\
\text { Died .. } \quad . . \\
\text { Mortality }\end{array}$ & $\begin{array}{l}\cdots \\
\cdots \\
. .\end{array}$ & $\begin{array}{l}\cdots \\
\cdots \\
\cdots\end{array}$ & $\begin{array}{c}27 \\
12 \\
44 \cdot 4 \%\end{array}$ & $\begin{array}{c}33 \\
12 \\
36 \cdot 4 \%\end{array}$ & $\begin{array}{c}13 \\
6 \\
46 \cdot 2 \%\end{array}$ & $\begin{array}{c}6 \\
3 \\
50 \%\end{array}$ \\
\hline $\begin{array}{l}\text { "Non-renal" } \\
\text { Number of patients } \\
\text { Died .. } \\
\text { Mortality }\end{array}$ & $\begin{array}{l}\cdots \\
\cdots \\
\cdots\end{array}$ & $\begin{array}{l}\cdots \\
\cdots \\
\cdots\end{array}$ & $\begin{array}{c}29 \\
4 \\
13 \cdot 8 \%\end{array}$ & $\begin{array}{c}80 \\
12 \\
15 \%\end{array}$ & $\begin{array}{r}106 \\
17 \\
16 \%\end{array}$ & $\begin{array}{c}37 \\
20 \\
54 \cdot 1 \%\end{array}$ \\
\hline $\begin{array}{l}\text { All known causes } \\
\text { Number of patients } \\
\text { Died } \ldots \\
\text { Mortality }\end{array}$ & $\begin{array}{l}\cdots \\
\cdots \\
\cdots\end{array}$ & $\begin{array}{l}\cdots \\
\cdots \\
\cdots\end{array}$ & $\begin{array}{c}56 \\
16 \\
25 \cdot 6 \%\end{array}$ & $\begin{array}{r}113 \\
24 \\
21 \cdot 2 \%\end{array}$ & $\begin{array}{c}119 \\
23 \\
19 \cdot 3 \%\end{array}$ & $\begin{array}{c}43 \\
23 \\
53 \cdot 5 \%\end{array}$ \\
\hline
\end{tabular}

TABLE III

Mortality in Relation to Height of Blood Pressure in Hypertensive Patients with Heart Failure

\begin{tabular}{|c|c|c|c|c|c|c|c|}
\hline \multirow{3}{*}{\multicolumn{2}{|c|}{ Cause of heart failure }} & \multicolumn{6}{|c|}{ Diastolic blood pressure level $(\mathrm{mm} / \mathrm{Hg})$} \\
\hline & & \multicolumn{2}{|c|}{ Men } & \multicolumn{2}{|c|}{ Women } & \multicolumn{2}{|c|}{ Total } \\
\hline & & $90-129$ & $>130$ & $90-129$ & $>130$ & $90-129$ & $>130$ \\
\hline $\begin{array}{llll}\text { "Renal" } & & \\
\text { Number of patients } \\
\text { Died } & . & . \\
\text { Mortality } & \ldots & .\end{array}$ & $\begin{array}{l}\cdots \\
\cdots \\
\cdots\end{array}$ & $\begin{array}{c}17 \\
9 \\
52 \cdot 9 \%\end{array}$ & $\begin{array}{c}30 \\
10 \\
33 \cdot 3 \%\end{array}$ & $\begin{array}{c}14 \\
5 \\
35 \cdot 7 \%\end{array}$ & $\begin{array}{c}18 \\
9 \\
50 \%\end{array}$ & $\begin{array}{c}31 \\
14 \\
45 \cdot 2 \%\end{array}$ & $\begin{array}{c}48 \\
19 \\
39 \cdot 6 \%\end{array}$ \\
\hline $\begin{array}{l}\text { "Non-renal" } \\
\text { Number of patients } \\
\text { Died } \\
\text { Mortality }\end{array}$ & $\begin{array}{l}\because \\
\cdots \\
.\end{array}$ & $\begin{array}{r}104 \\
23 \\
22 \cdot 1 \% \\
\end{array}$ & $\begin{array}{c}30 \\
7 \\
23 \cdot 3 \%\end{array}$ & $\begin{array}{c}101 \\
20 \\
19.8 \%\end{array}$ & $\begin{array}{c}17 \\
3 \\
17.6 \%\end{array}$ & $\begin{array}{c}205 \\
43 \\
20.8 \%\end{array}$ & $\begin{array}{c}47 \\
10 \\
21 \cdot 3 \%\end{array}$ \\
\hline $\begin{array}{l}\text { All known causes } \\
\text { Number of patients } \\
\text { Died } \\
\text { Mortality }\end{array}$ & $\begin{array}{l}. \\
. \\
.\end{array}$ & $\begin{array}{c}121 \\
32 \\
26 \cdot 5 \%\end{array}$ & $\begin{array}{c}60 \\
17 \\
28 \cdot 3 \%\end{array}$ & $\begin{array}{c}115 \\
25 \\
21 \cdot 7 \%\end{array}$ & $\begin{array}{c}35 \\
12 \\
34 \cdot 3 \%\end{array}$ & $\begin{array}{c}236 \\
57 \\
24 \cdot 1 \%\end{array}$ & $\begin{array}{c}95 \\
29 \\
30 \cdot 5 \%\end{array}$ \\
\hline
\end{tabular}

Advancing age did not effect the outcome in the renal group, 76 per cent of whom were less than 60 years of age.

(c) Blood pressure level. In order to assess the effect of the blood pressure upon the mortality, the percentage of deaths was calculated below and above an arbitrary diastolic pressure level of 130 .

For all patients with a known cause of heart failure, the mortality rate was higher in the diastolic range above $130 \mathrm{~mm} / \mathrm{Hg}$ (Table III). Further analysis revealed that this pressure range contained a relatively larger proportion of patients with renal disease than did the pressure range below 130 . Although comprising only 23 per cent of the whole series, the renal group contributed as many as 48 of the 95 patients with diastolic pressure above 130 but only 31 of the 246 patients with pressures below this level.

The adverse effect of high blood pressure upon mortality was more conspicuous in women; 22 per cent died with diastolic pressures below, compared with 34 per cent in those with pressures above 130 . In men the corresponding rates were 26.5 per cent and 28.3 per cent. Again this apparent sex difference could be explained by the relatively larger proportion of patients with renal 
lesions amongst the women who died in the higher pressure range as compared with men (Table III). Furthermore the mortality in women with renal disease and diastolic pressures above 130 was greater than that for corresponding men.

It seemed possible that the increased mortality for patients in the renal group might be accounted for by the relatively larger proportion with very high blood pressures in this group as compared with the non-renal group. This, however, was not the explanation since death occurred in 45 per cent of patients in the renal group with diastolic pressures below as compared with 40 per cent with pressures above 130 . Indeed when renal and non-renal groups were considered separately, the height of the blood pressure did not influence the death rate in either group (Table III).

\section{Discussion}

As an isolated burden, high blood pressure was an infrequent cause of heart failure in this series. Additional myocardial injury was required to initiate failure.

In half the cases this additional stress was provided by cardiac ischæmia, and in a further 14 per cent ischæmia probably contributed to the development of failure. This is in keeping with numerous published reports regarding the frequent association between high blood pressure and coronary arterial disease. Thus Zinn and Cosby (1950) reported antecedent hypertension in 64 per cent of patients with coronary disease; similar estimates include 58 per cent (Wartman and Hellerstein, 1949), 57 per cent (Greisman and Rosenfield, 1948), 54 per cent (Billings et al., 1949) and 41 per cent (Wright et al., 1954). Donald (1945) concluded that "hypertension preceded coronary occlusion in 25-75 per cent of cases as compared with a hypertension incidence rate of 2-11 per cent of the general population". At necropsy Averbuck (1936) found severe coronary atheroma in 85 per cent of patients with essential hypertension and heart failure, but only 10 per cent of those without cardiac failure had similar coronary disease.

A renal element was responsible for heart failure in 79 patients ( 23 per cent) in this series. The mechanism by which kidney disease induces failure is not known. The height of the blood pressure might have contributed to failure in these cases since renal disease was associated with high pressure levels; 62 per cent had diastolic pressures above 130 as compared with an incidence of 19 per cent for patients in the non-renal group. This explanation could not however account for failure that occurred in the 38 per cent of the renal group with diastolic pressures below 130. Friedberg (1950) could find no correlation between the grade of hypertension and the presence or severity of heart failure amongst patients with essential hypertension, and similar findings have been reported in acute renal disease (Levy, 1930; Whitehill et al., 1939; Odel and Tinney, 1943). It has been suggested that œdema of the myocardium might weaken ventricular contraction (Friedberg, 1950). Alteration of the electrolyte concentrations in the body's fluid compartments, secondary to renal disease, could explain the deficiency of myocardial contraction.

The most conspicuous finding among patients with renal disease was their high mortality. A "renal" cause of failure reduced the average age at death by 12 years and doubled the mortality rate in comparison with patients in the "non-renal" group. This high mortality was due to uræmia which occurred in 20 of the 33 deaths in the renal group. The insidious development or aggravation of uræmia was not only favoured by the presence of cardiac failure but in some cases unavoidably encouraged by the treatment which included fluid restriction.

Advancing age was associated with a slight increase in mortality in the non-renal group of patients, the rate of increase, however, was not significant and in any event was no more than expected for the general population of corresponding age. The adverse effects of age were greatly out-weighed by the renal factor.

A probable but not significant, increase in mortality was found with increasing blood pressure when all patients were considered and also among the women. This finding agrees with the views of Bechgaard et al. (1956) and with those of Pickering (1955) who considered the height of the blood pressure foremost when summarizing the factors affecting the prognosis in hypertension. 
It was possible, however, to account for the worsening prognosis with rise of pressure by the distribution of patients with renal lesions in these groups. Furthermore, the height of the blood pressure did not affect the mortality in patients with renal disease; in both renal and non-renal groups the proportion of deaths did not rise with increase in blood pressure (Table III).

The increased risk of death among those patients with very high blood pressure in this series was attributed, not to the height of the blood pressure per se, but to the co-existence of a renal lesion. The apparent importance of high blood pressure was due to the common association between a very high arterial pressure and renal disease.

It is perhaps significant that ganglion blocking agents had not been administered to those in whom no precipitating cause of failure was discovered. In these patients inability of the coronary arterial flow to keep pace with the work demands of a hypertrophied myocardium probably accounted for the onset of failure. It is possible that heart failure would have been avoided had they received hypotensive therapy. That simple overstrain must be a major influence is shown by the work of Smirk (1954) and Shirley Smith et al. (1954), who have demonstrated the virtual disappearance of hypertensive heart failure as a cause of death when ganglion blocking agents are effectively used. Of the ten patients who died in persistent failure in this series only one received hypotensive therapy.

\section{SUMMARY}

In a series of 341 patients with high blood pressure and heart failure a cause of failure in addition to hypertension was found in all but 10 ( 3 per cent).

Ischæmic heart disease precipitated heart failure in half the patients, and in a further 14 per cent it probably contributed to the development of failure.

Other important causes of heart failure were, valvular heart disease, renal disease alone or combined with cardiac lesions, malignant hypertension, and respiratory infections. The remaining less frequent causes of heart failure were combined to form a miscellaneous group.

The presence of a renal lesion doubled the mortality rate and reduced by 12 years the average age at death when compared with patients with no renal damage. Patients with evidence of renal disease had the highest blood pressures. The worsening prognosis of patients with hypertension and heart failure with increasing blood pressure levels was shown to be due to the presence of a renal lesion rather than the height of the blood pressure per se.

I wish to thank the Physicians of Charing Cross Hospital for allowing me access to the case notes of the patients in this series. In particular, I am indebted to Dr. P. B. S. Fowler for permission to study patients in the Hypertension Clinic, and to Dr. K. Shirley Smith for advice and criticism.

\section{REFERENCES}

Averbuck, S. H. (1936). Amer. Heart J., 11, 99.

Bechgaard, P., Kopp, H., and Neilson, J.' (1956). Acta. med. scand., Vol. 154, Sup. 312, para. 165.

Bell, E. T., and Clawson, B. J. (1928). Arch. Path., 5, 938.

Billings, F. T., Kalstone, B. M., Spencer, J. L., Ball, C., and Meneely, G. R. (1949). Amer. J. Med., 7, 356.

Clawson, B. J. (1941). Amer. Heart J., 22, 607.

Donald, T. C., Jr. (1945). New Orleans med. surg. J., 98, 209.

Fahr, G. (1935). J. Amer. med. Ass., 105, 1396.

Fishberg, A. M. (1940). Heart Failure. 2nd ed., p. 439. Henry Kimpton, London.

Friedberg, C. K. (1950). Diseases of the Heart., p. 79. W. B. Saunders Co., Philadelphia.

Greisman, H., and Rosenfield, S. Z. (1948). New York State J. Med., 48, 1277.

Hamilton, M., Pickering, G. W., Roberts, J. A. F., and Sowry, G. S. C. (1954). Clin. Sci., 13, 11.

Levy, I. J. (1930). Amer. Heart. J., 5, 277.

Murphy, F. D., Grill, J., Pessin, B., and Moxon, G. (1932). Ann. intern. Med., 6, 31.

Odel, H. M., and Tinney, W. S. (1943). Amer. Heart J., 26, 239.

Pickering, G. W. (1955). High Blood Pressure. J. and A. Churchill, London.

Smith, K. Shirley, Fowler, P. B. S., and Edmunds, V. (1954). Brit. med. J., 2, 1243.

Smirk, F. H. (1954). Brit. med. J., 1, 717.

Wartman, W. B., and Hellerstein, H. K. (1949). Ann. intern. Med., 28, 41.

Whitehill, M. R., Longcope, W. T., and Williams, R. (1939). Bull. Johns Hopkins Hosp., 64, 83.

Wright, I. S., Marple, C. D., and Beck, D. F. (1954). Myocardial Infarction. Its Clinical Manifestations and Treatment with Anticoagulants. A Study of 1031 cases. Grune and Stratton, New York.

Zinn, W. J., and Cosby, R. S. (1950). Amer. J. Med., 8, 169, 177. 